\title{
Absorber Thickness Effect on The Effectiveness of Solar Collectors to Production Hot Air For Drying
}

\author{
Ahmad Syuhada ${ }^{1}$ and Muhammad Ilham Maulana ${ }^{2}$ \\ ${ }^{1,2}$ Mechanical Engineering of Syiah Kuala University, Darussalam-Banda Aceh 23111, Indonesia
}

\begin{abstract}
One way to increase the drying rate using a solar collector is to increase the air temperature of the collector and the time of circulation of hot air delivered to the drying chamber. The optimization of heat absorber by utilizing solar energy has been shown to be strongly influence by fluid flow characteristics in the collector channel. This study examined the sharp turning channel on the air passage of a solar collector. Collector size used was $305 \mathrm{~cm} \times 80 \mathrm{~cm}$ and had 10 sharp turning channel baffles. Solar radiation absorbent material used in this collector test is iron sand with three thickness variations, namely 3,6 , and $9 \mathrm{~cm}$. The measurement results show that the air temperature that can be produced by the collector with a thickness of $3 \mathrm{~cm}$ absorber reaches 85 degree Celsius with an effective drying time of 8 hours and the final air temperature testing on the collector out side still reaches about 40 degree Celsius at air temperature of 32 degree Celsius. At a thickness of $6 \mathrm{~cm}$ absorber, the air temperature inside the collector was about 83 degrees and the duration of 10 hours of drying time, with the collector-out air temperature around 39 degree Celsius at the air temperature of 30 degree Celsius. In contrast to the $9 \mathrm{~cm}$ thickness of the absorber, the drying air temperature was only 81 degree Celsius and the drying time was 12 hours and the final air temperature measurement was 40 degree Celsius at the ambient temperature was 27 degree Celsius. This result can be seen as the effect of thick collector absorber on solar thermal energy that can also be absorbed by absorber solar collector.
\end{abstract}

\section{Introduction}

Drying by using a solar collector could increase a higher drying temperature when compared with natural drying in the sun that relatively low water and can accelerate the decrease in moisture content of the material being dried [1]. For drying conditions using a solar collector, drying air temperature can reach 45-60 degree Celsius [2,3]. While in the case of fruit dryers, the maximum temperature reached is 57 degree Celsius and takes 24 hours [4]. While the drying process with a temperature of 50 degree Celsius, to reduce the water content from $80 \%$ to $9 \%$ takes 56 hours [5]. To increase the drying rate requires high collector exit temperature. Research has been done with the use of solar collector technique using multi channel technology sharp turn, so that obtained air temperature at solar collector can reach above 80 degree Celsius [6,7,8].

Many studies have been done on high-speed streams with forced convection heat transfer. Applications of such research are usually for high technology often designed in developed countries such as the internal cooling of gas turbines. For forced heat transfer / masses, the issues examined is the Reynolds (Re) number for obtaining Nusselt $(\mathrm{Nu})$ for the determination of heat transfer characteristics, and Sherwood (Sh) for the assessment of heat transfer characteristics [7,8,9]. But its application to medium technology as well as for cooling and heating processes using energy burning fuel and it is still very rare.

Besides flow patterns that affect heat transfer characteristics in solar collectors with sharp turning, the use of absorber in solar collectors has an important role in increasing heat transfer in solar collectors. An absorber tube with vacuum reduces significantly the heat losses in comparison with broken tube or tube without vacuum. During power plant operation poor isolation or any glass tube failure should be avoided for any solar thermal power plants. (10). An experimental investigation has been carried out for a range of system and operating parameters in order to analyse the effect of artificial roughness on heat transfer and friction characteristics in solar air heater duct which is having dimple shaped elements arranged in angular fashion (arc) as roughness elements on absorber plate. Duct has an aspect ratio $(\mathrm{W} / \mathrm{H})$ of 11 , relative roughness pitch $(\mathrm{p} / \mathrm{e})$ range of $10-20$, relative roughness height $(\mathrm{e} / \mathrm{D})$ range of $0.021-0.036$, arc angle (a) range of 45-75 degree and Reynolds number (Re) ranges from 3600 to 18,000. [11].

Experimental investigation of overall performance efficiency and reliability of five types of solar collectors was carried out. The systems involved in this study were

\footnotetext{
Corresponding author: syuhada_mech@yahoo.com
} 
blue and black coating-selective copper, copper, and aluminium collectors in addition to evacuated tubes collectors. The experiments were carried out during April under same conditions for all collectors. Considering size of application, cost of appliance, quality and maintenance follow-up, results show that evacuated tube, blue and black coating-selective copper collectors are recommended for medium and large scale applications due to their long life, high efficiency ease of maintenance. Aluminium collectors are recommended for small applications like houses (12).

Thermal performance of a single and double pass solar air heater with fins attached and using a steel wire mesh as absorber plate was investigated experimentally. Result shows that, the efficiency increase with increasing air mass flow rate. (13). Experimental studies were carried out to investigate the effects of micro-channel geometry on the thermal and hydraulic performance of absorber plates for compact (thin and light-weight) solar thermal collectors. The results showed a Reynolds number dependent Nusselt number; this was due to axial thermal conduction. The Nusselt number was observed to increase as the aspect ratio approached unity. Measured friction factors were similar in trend to the predictions for rectangular channels, although the overall rise in fluid temperature resulted in slightly lower friction factors. The results showed that thermal improvement can be achieved by increasing the fluid velocity. The results are beneficial for the design of micro-channel absorber plates [14].

An experimental study of thermo-hydraulic performance of a solar air heater with $60 \mathrm{v}$-down discrete roughness on the airflow side of the absorber plate along that for a smooth duct air heater. The enhancement in the thermal efficiency due to the roughness on the absorber plate was found to be 12.5$20 \%$ depending on the airflow rate; higher enhancement is at the lower flow rate. The results of a detailed thermohydraulic performance study of solar air heater with vdown discrete rib roughness using the mathematical model are also presented along with the effect of variation of various parameters on the performance. [15]

Therefore, an experimental study is needed to make clear the effect of solar collector absorber thickness on the characteristics of local (mass) heat transfer in rectangular channels with sharp turn angles.

Furtheremore, in the assessment of heat transfer in sharp turning channels for the case of solar collectors, the necessary thing for natural heat transfer / mass of convection is the measurement of local temperature distribution, so that the flow field characteristics can be predicted. Specification of solar collector test as performed by [16] with a sharp bend angle of 130 degree with a thickness of $3 \mathrm{~cm}, 6 \mathrm{~cm}$ and $9 \mathrm{~cm}$ absorber.

The purpose of this study is to optimize the heat absorption from solar collector absorber with the technique of sharp multi turn channels. By understanding the characteristics of the effect of the thickness of the absorbent material and the position of the channel on the ability of heat absorption, an optimum absorbing system will be obtained.

\section{Methodology}

\subsection{Experimental Set Up}

This study used an equipment as a heat absorber medium solar collector by utilizing the panel which was made from wooden frame with insulation of rubber material. As an absorber, iron sand was used as show in Fig. 1. The size of the collector was $305 \mathrm{~cm} \mathrm{x} 80 \mathrm{~cm}$. On each side of the absorber box was coated with thermal insulator in the form of black colour rubber with a thickness of $10 \mathrm{~mm}$. Iron sand used as a solar radiation absorber had a thickness of $3 \mathrm{~cm}, 6 \mathrm{~cm}$ and $9 \mathrm{~cm}$ to see the effect of thickness on the ability of heat absorption. The iron sandbox was made of wood with a thickness of $15 \mathrm{~mm}$ and as a transparent cover was used $5 \mathrm{~mm}$ glass with a size of $305 \mathrm{~cm} \times 80 \mathrm{~cm}$. The position of the air heater box was tilted 15 degree against the horizontal axis with the aim that the airflow process could take place because of the difference in input and output elevation.

This study modified the temperature distribution of quadrangle channel by addition of buffer arrangement in the form of a sharp multi-turn channel with angle of 130 degree).

As measuring equipment used thermocouple and mercury thermometer that had a temperature range of 0 110 degree Celsius, the position of the thermometer sensor placement or temperature measuring point was placed according to the condition of the heating conduit along the passage on the collector. Experimental tests were conducted in the environment by using as heating energy and temperature measurements are held at several points on the flow path. For measurements temperatures of 130-degree sharp turn channel that used 9 obstacles and 20 thermometer sensor points. The laying of the obstacles and schematic measurement points can be seen in Fig. 1.

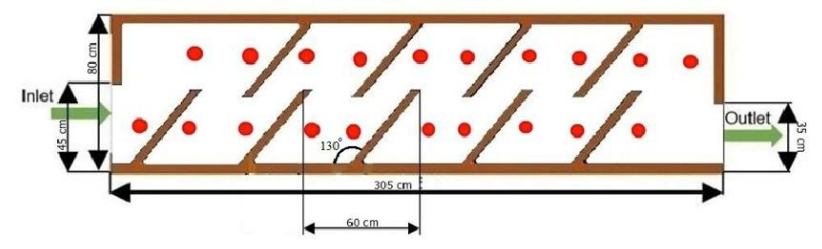

Fig. 1. Layout of obstacle and position of temperature measurement on sharp turn collector channel with 130-degree resistance angle

\subsection{Measurement Techniques and Data Analysis}

Temperature measurements on heat absorber by utilizing solar energy awere conducted every half hour from 10 am to $10 \mathrm{pm}$ where the intensity of solar heat during testing ranges from 82 to $926 \mathrm{~W} / \mathrm{m} 2$. At 12 am the intensity is $900 \mathrm{~W} / \mathrm{m} 2$, at $1 \mathrm{pm}$ the intensity reached $926 \mathrm{~W} / \mathrm{m} 2$ and at $2 \mathrm{pm}$ the intensity is $900 \mathrm{~W} / \mathrm{m} 2$. The test was carried out with three instrument conditions by varying the thickness of iron sand used as the absorber in the channel that is $3 \mathrm{~mm}, 6 \mathrm{~mm}$ and $9 \mathrm{~mm}$. From the three variations of solar collector tool that used source of solar heat would be known the characteristics of fluid 
movement and distribution on the various channel position. Finally, the most optimal heat absorbing system among the three-absorber thicknesses used can be obtained.

Processing or data analysis was the final stage of research methodology. The data obtained from the test then plotted in the form of graphs, which then carried out the discussion and viewed the comparison between each treatment condition.

The amount of the sun intensity energy absorbed by the solar collector absorber is: $\mathrm{Q}_{\mathrm{ab}}=\mathrm{m} \mathrm{C}\left(\mathrm{T}_{\text {absorber }}\right.$ $\left.\mathrm{T}_{\text {environmental }}\right) . \mathrm{Q}_{\mathrm{ab}}=$ the amount of heat the intensity of the sun absorbed by the absorber, $\mathrm{m}=$ mass of absorber / iron sand, $\mathrm{C}=$ heat conductivity of absorber (iron sand), $\mathrm{T}_{\text {absorber }}=$ temperature absorber heated by collector and $\mathrm{T}_{\text {environmental }}=$ air temperature outside the collector. $\mathrm{C}=$ $0.52 \mathrm{~kJ} / \mathrm{kg}$. K. Iron sand density $=2722 \mathrm{~kg} / \mathrm{m}^{3}$. The volume of iron sand on the thickness of absorber $3 \mathrm{~cm}$ is $0.072 \mathrm{~m}^{3}$, for a thickness of $6 \mathrm{~cm}$ is $0.144 \mathrm{~m} 3$ and for thickness $9 \mathrm{~cm}$ is $0.216 \mathrm{~m} 3$.

Heat Energy that heats the air by a collector is $Q_{\text {air }}=$ $\mathrm{m} \mathrm{C}_{\mathrm{p}}$ ( $\mathrm{T}$ air inside the collector - $\mathrm{T}$ the air outside the collector). $\mathrm{Q}$ air $=$ the amount of heat absorbed by the air inside the collector. $\mathrm{T}_{\text {in }}=$ temperature inside the collector / absorber, $\mathrm{m}=$ the amount of air mass flowing in the collector. $\mathrm{C}_{\mathrm{p}}=$ air conductivity.

With the increasing amount of solar intensity that can be absorbed by the solar collector absorber, the ability of the absorber to heat the air in the solar collector is increasing as well.

\section{Results and Discussions}

The temperature distribution of the absorber along the collector heater channel affects the distribution of hot air through the channel. In this case the measurement starts from the position after the inlet until the position near the outlet.

The characteristics of heat transfer within the solar collector passage affect the distribution of air temperature within the channel path. The absorption and release of heat by the solar collector absorber by utilizing solar energy is influenced by several characteristics of fluid flow and absorber used in the channel. This is due to the specific heat of the material and the mass of iron sand used as the absorber. Thus, if the temperature distribution along the channel can be known then the characteristics of heat transfer within the channel can be predicted.

\subsection{Temperature Distribution along Solar Collector Channel with Variation of Absorber Thickness}

Measurement of temperature distribution is done on channel of solar collector channel having angle of resistance 130 degree and three variations of iron sand absorbent thickness that are 3,6 and $9 \mathrm{~cm}$. Figure 2 shows the temperature distribution occurring on a solar collector channel with a 130-degree resistance angle and a $3 \mathrm{~cm}$ thick iron sand thickness. Measurements are conducted from 10 am to $8 \mathrm{pm}$ because the temperature distribution is no longer changed after $8 \mathrm{pm}$. From the temperature distribution in Fig. 2, it is clear that the distribution of air temperature from 10 am to $13 \mathrm{pm}$ inside the collector outlet is 85 degrees Celsius, slightly higher than the absorbent temperature of 83 degrees Celsius. While at $13.30 \mathrm{pm}$ the absorber temperature only reaches 84 degrees Celsius, when the temperature of hot air within the collector channel is 83 degrees Celsius. This happens because the highest intensity of the sun occurs at 13.00 reaches $926 \mathrm{~W} / \mathrm{m} 2$.

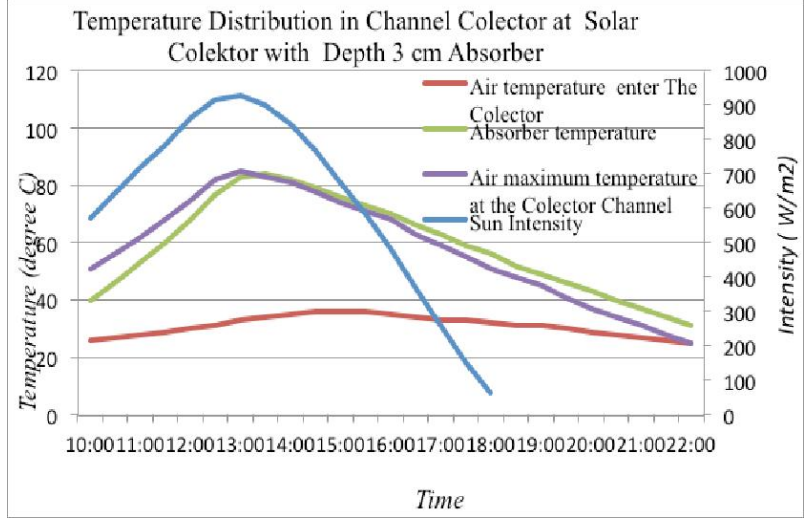

Fig. 2. Temperature Distribution On Solar Collector Channel With Thickness Of Absorbent $3 \mathrm{Cm}$

The high intensity of the sun that enters the solar collector causes solar thermal radiation other than heating the absorber that the solar radiation reflected by the absorber also reheats the air flowing in the collector passage. Thus, the air flowing in the passage of the collector channel in addition to receiving the convection heat from the absorber is also a great radiant heat from the direct radiation of the eye of the day and the reflection radiation from the absorber.

After $2 \mathrm{pm}$ the distribution of absorber temperature and air temperature in the collector passage changed, where the temperature of absorber 84 degree Celsius, it starts higher than the temperature of hot air in the collector of 83 degree Celsius. This is due to the intensity of the sun begans to fall after $1 \mathrm{pm}$. So, at 1.30 $\mathrm{pm}$ the intensity of the eye has become $900 \mathrm{~W} / \mathrm{m} 2$. The intensity of the sun continues to decline to reach the lowest value at $6 \mathrm{pm}$ that is equal to $60 \mathrm{~W} / \mathrm{m} 2$. Although the intensity of the sun is very small the absorber still heats the air on the collector, the absorber still keeps the heat. So, the collector is still able to heat the air until at $8 \mathrm{pm}$ where the temperature of the absorber still reaches 43 degrees Celsius and the heating air temperature in the collector's channel still reaches 37 degrees Celsius on condition of outside air temperature 27 degree Celsius.

Figure 3 shows the results of temperature distribution measurements occurring on a solar collector passage channel with a 130-degree resistance angle and a thickness of $6 \mathrm{~cm}$ iron sand absorber. Data collection is carried out from 10 am to $9 \mathrm{pm}$, because the temperature distribution did not changed after $9 \mathrm{pm}$. From the temperature distribution in figure 3 it is clear that from 10 am to $2 \mathrm{pm}$ the air temperature inside the collector 
duct is 83 degrees Celsius, higher than the absorber temperature of 80 degree Celsius. At 14 pm the absolute temperature of the absorber is 80 degree Celsius, higher than the temperature of hot air within the channel of the collector channel, which is 79 degree Celsius. This happens the same as in the case of the $3 \mathrm{~cm}$ thickness of the absorber, which is the effect of the decreasing of eye intensity value after $1 \mathrm{pm}$.

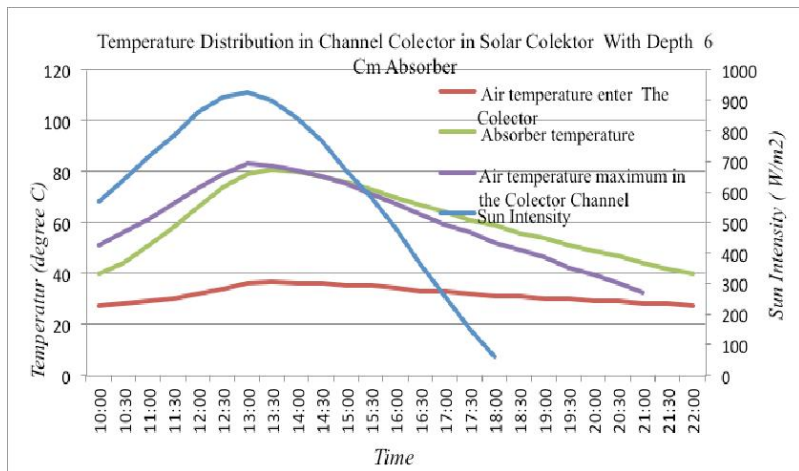

Fig. 3. Temperature Distribution On Solar Collector Channel With Thickness Of Absorber $6 \mathrm{Cm}$

Temperature distribution measurement result in the solar collector channel with the 130-degree resistance angle and the thickness of the $9 \mathrm{~cm}$ iron sand absorbent has been shown in Fig. 4. The measurement parameters taken include the collector inlet air temperature, the absorber temperature and the highest air temperature in the collector channel. The intensity of sunlight during the study was also measured as comparison data.

Figure 4 shows the results of temperature distribution measurements occurring on a solar collector passage channel from 10 am to $9 \mathrm{pm}$. From the distribution of the temperature it is clear that from 10 am to $1 \mathrm{pm}$, the temperature of the air in the channel of the chamber reaches 81 degrees Celsius, higher than the absorber temperature that only 75 degrees Celsius. While at 1.30 $\mathrm{pm}$ the absorber temperture still rises to 79 degrees Celsius, slightly lower than the temperature of hot air in the channel of collector channel which began to drop to 80 degree Celsius from the previous 81 degree Celsius at $1 \mathrm{pm}$. However, at $2 \mathrm{pm}$ the absorber temperature still reaches 79 degree Celsius, slightly higher than the temperature of hot air within the channel of the collector channel, which is 78 degree Celsius. This happens the same as in the case of the thickness of absorber $3 \mathrm{Cm}$ and $6 \mathrm{Cm}$ that is due to the influence of the decrease in the intensity of the sun after $1 \mathrm{pm}$.

The intensity of sunlight continued to decline during the test and reached a low of $60 \mathrm{~W} / \mathrm{m} 2$ at $6 \mathrm{pm}$. Although the intensity of the sun is very small at the time, but the absorbent material still keeps the heat so it is still able to provide heat to the air inside the collector. This condition allows absorber with a temperature of 48 degrees Celsius is still able to heat the air in the solar collector to reach 40 degrees Celsius until $10 \mathrm{pm}$ at 27 degrees Celsius outside air temperature.

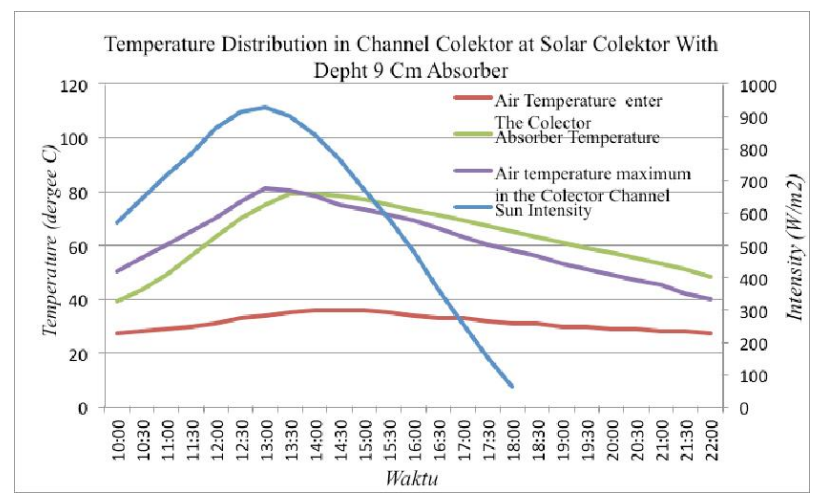

Fig. 4. Temperature Distribution on Solar Collector Channel with Thickness of Absorber $9 \mathrm{Cm}$

\subsection{Optimize the effect of the absorber thickness in the Collector Channel}

To find out which type of the best solar collector in terms of dryer air heater, it needs to examine the flow patterns within the solar collector passage and heat transfer characteristics. It also need to understand the effect of the absorber system used on the collector. This is because the absorbent characteristic used for the absorption of radiant heat in the solar collector greatly affects the rate of heat absorption which is influenced by changes in its specific heat properties and thermal conductivity. The heat absorption capacity of radiation from the sun by the absorber is heavily dependent by the absorbent specific mass and heat, so it depends on the depth of the absorbent used on the collector.

Figure 5 shows the temperature distribution of absorber with variation of absorbent depth of $3 \mathrm{~cm}, 6 \mathrm{~cm}$ and $9 \mathrm{~cm}$, at measurement time from 10 am to $10 \mathrm{pm}$. Although the absorber has been irradiated by the sun's hot intensity energy since $9 \mathrm{am}$, the intensity of the sun begins to be measured from $10 \mathrm{am}$ to $6 \mathrm{pm}$. The intensity of the sun at $10 \mathrm{am}$ is $570 \mathrm{~W} / \mathrm{m} 2$ and continues to increase until it reaches its maximum value at $1 \mathrm{pm}$ with an intensity of $926 \mathrm{~W} / \mathrm{m} 2$. After that the radiation heat intensity continued to decrease to $60 \mathrm{~W} / \mathrm{m} 2$ at $6 \mathrm{pm}$.

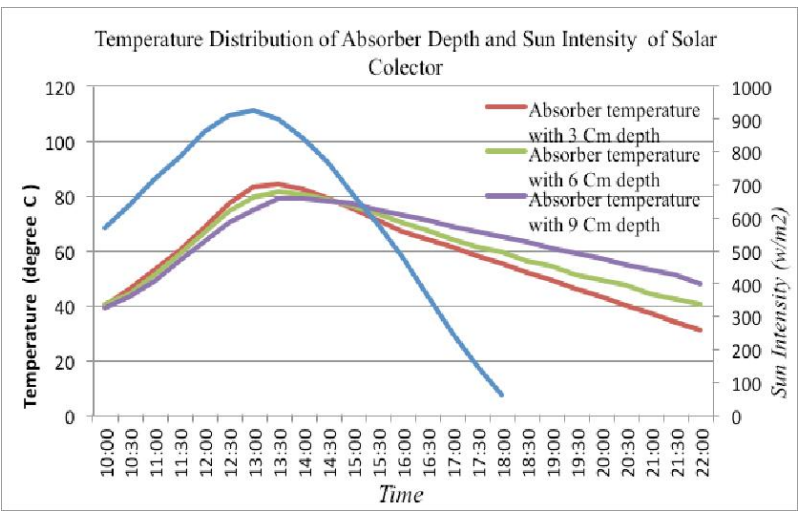

Fig. 5. Temperature Distribution On Solar Collector Channels With Absorbent Thickness 3, 6, and $9 \mathrm{Cm}$

The temperature of the solar collector with a $3 \mathrm{Cm}$ absorbent thickness is 40 degrees Celsius at 10 am and 
continues to increase over time until it reaches the highest value of 84 degrees Celsius at $1 \mathrm{pm}$. After reaching its maximum point, the temperature distribution continues to decline until it reaches 31 degrees Celsius at $10 \mathrm{pm}$. The same condition occurs in the absorber solar collector with a $6 \mathrm{~cm}$ thick absorbent thickness, the absorbent temperature of 40 degrees Celsius at 10 am and reaches a high of 82 degrees Celsius at $1 \mathrm{pm}$. However, the maximum temperature achieved is 2 degrees Celsius lower than the absorbent with a thickness of $3 \mathrm{~cm}$. Then after $1 \mathrm{pm}$, the temperature distribution drops to 40 degrees Celsius at $10 \mathrm{pm}$.

In a solar collector with $9 \mathrm{Cm}$ absorbent thickness, the temperature at $10 \mathrm{am}$ is 39 degrees Celsius and continues to increase over time until it reaches a peak of 79 degrees Celsius at $1 \mathrm{pm}$. This maximum temperature value is 2 degrees lower than the temperature at the $6 \mathrm{~cm}$ thickness absorbent. However, after that, the temperature distribution decreased to 48 degree Celsius at $10 \mathrm{pm}$. At the moment, the temperature is 8 degrees Celsius higher than the absorbent with a thickness of $6 \mathrm{~cm}$ and higher by 15 degrees Celsius than the absorbent with a thickness of $3 \mathrm{~cm}$.

This figure showed that the maximum temperature in the air within the collector occurred in the absorber of the smallest mass with a $3 \mathrm{Cm}$ absorbent thickness. The highest temperature reached by collector was 85 degrees Celsius, but the effective heating mass of air by the collector occurred only for 8 hours. While the lowest air temperature in the collector occurs when the absorbent in the collector has a thickness of $9 \mathrm{Cm}$ with the largest absorbent mass than the other. The temperature generated under these conditions is 81 degrees Celsius with effective heating of air within the collector lasting up to 12 hours.

Based on the above conditions, can be formulated a phenomenon that occurs for the optimization of heating air through the path of the solar collector channel based on the absorbent mass used. The heat sink is the most important part of the solar collector system used as an air heater for drying. The absorber function other than as a solar radiant heat absorber and convert heat to air on the solar collector channel, it can also serve as an additional heater at low intensity. This is because in addition to releasing heat into the air, the channel with an absorber also stores heat received from the sun when the intensity of radiation is still high. So even in the afternoon or night time when the radiation intensity is small, the absorber can still heat the air because of the heat still stored in the absorber. It also proves that the more absorbent material used in the collector, the more heat is absorbed and stored by the absorber collector so that more heat is released to the air, even though the maximum temperature reached is smaller.

The results show that the capacity of the collector absorber mass plays an important role on the collector's ability to absorb the heat of the solar intensity by the solar collector. It is evident that in collectors with larger absorber masses the intensity of the sun that occurs greater so that the collector able to heat the air on the collector even though the intensity of the eyes of the day was not there or already night. This is in accordance to the existing thermodynamic theory.

\section{Conclusions}

1. Absorber has a very important role in a collector solar system as well as serves as an air heater for dryers.

2. In addition to converting heat to air, the absorber also stores the heat received from the sun when the intensity of irradiation is still high. So when the radiation intensity is small, the absorber is still able to heat the air as long as the absorber temperature is still high.

3. The highest temperature of air in the collector occurs at the largest absorbent mass with a thickness of $3 \mathrm{~cm}$ that is 85 degree Celsius but the effective air heating mass for only 8 hours.

4. The lowest air temperature in the collector occurs in the absorber of the largest absorbent mass with a thickness of $9 \mathrm{Cm}$. The air temperature is 81 degrees Celsius, with effective heating time of air by collectors reaching 12 hours.

The authors are grateful for the contributions of all the students at the Graduate School of Mechanical Engineering, Syiah Kuala University in this study.

\section{References}

1. Stiling, James, Simon Li, Pieter Stroeve, Jim Thompson, Bertha Mjawa, Kurt Kornbluth, and Diane M. Barrett. "Performance evaluation of an enhanced fruit solar dryer using concentrating panels." Energy for sustainable development 16, no. 2 (2012): 224-230.

2. Gutti, Babagana, Silas Kiman, and Ahmed M. Murtala. "SOLAR DRYER-AN EFFECTIVE TOOL FOR AGRICULTURAL PRODUCTS PRESERVATION." Journal of Applied Technology in Environmental Sanitation 2, no. 1 (2012).

3. Hussain, Muhammad Ibrar, Esmail MA Mokheimer, and Shakeel Ahmed. "Optimal Design of a Solar Collector for Required Flux Distribution on a Tubular Receiver." Journal of Energy Resources Technology 139, no. 1 (2017): 012006.

4. Alleyne, Fatima S., and Rebecca R. Milezarek. "Design of solar thermal dryers for 24 hour food drying." United State Department of Agriculture, Heating Processed Food Research Unit (2015).

5. Prakash, T. B., and S. Satyanayarana. "Performance analysis of solar drying system for Guntur Chili." Int J Latest Trends Eng Technol 4 (2014): 283-298.

6. Syuhada A. and Maulana M.I. Characteristics of Heat Transfer On Solar Collector Channel By Using A Sharp Turn, The International Conference on Thermal Science and Technology (ICTST) 2017, November 17-19th, (2017). 
7. Ji, Xu, Ming Li, Yunfeng Wang, Deli Ling, and Xi Luo. "Performance characteristics of solar drying system for agricultural products." BULGARIAN CHEMICAL COMMUNICATIONS 48 (2016): 120-125.

8. Tiwari, Anupam. "A review on solar drying of agricultural produce." journal of food (2016).

9. Teja, Ravi, F. Z. Pathan, and Mandar Vahadne. "Optimization of Heat Transfer through Rectangular Duct." International Research Journal of Engineering and Technology (IRJET) 2, no. 4 (2015): 1906-1910.

10. M. Yaghoubi, F. Ahmadi, and M. Bandehee, 2013, Analysis of Heat Losses of Absorber Tubes of Parabolicthrough Collector of Shiraz (Iran) Solar Power Plant , Journal of Clean Energy Technologies, Vol. 1, No. 1, January 2013

11. Muneesh Sethi, Varun, N.S. Thakur, 2012, Correlations for solar air heater duct with dimpled shape roughness elements on absorber plate, Solar Energy 86 (2012) 2852-2861.

12. Sakhrieh, A. Al-Ghandoor, 2013, Experimental investigation of the performance of five types of solar collectors, Energy Conversion and Management 65 (2013) 715-720

13. A.P. Omojaro, L.B.Y. Aldabbagh, 2010, Experimental performance of single and double pass solar air heater with fins and steel wire mesh as absorber, Applied Energy 87 (2010) 3759-3765.

14. M.A. Oyinlola, G.S.F. Shire, R.W. Moss. 2015, Investigating the effects of geometry in solar thermal absorber plates with micro-channels, International Journal of Heat and Mass Transfer 90 (2015) 552-560

15. Rajendra Karwa \& Girish Chitoshiya, 2013, Performance study of solar air heater having vdown discrete ribs on absorber plate, Energy 55 (2013) 939-955.

16. Dara, J. E., K. O. Ikebudu, N. O. Ubani, C. E. Chinwuko, and O. A. Ubachukwu. "Evaluation of a passive flat-plate solar collector." Int. J. of Advancements in Res. \& Tech 2, no. 1 (2013).

17. Syuhada, A., M. Hirota, H. Fujita, S. Araki, M. Yanagida, and T. Tanaka. "Heat (mass) transfer in serpentine flow passage with rectangular crosssection." Energy conversion and management 42, no. 15-17 (2001): 1867-1885.

18. Hirota, M., H. Fujita, A. Syuhada, S. Araki, T. Yoshida, and T. Tanaka. "Heat/mass transfer characteristics in two-pass smooth channels with a sharp 180-deg turn." International Journal of Heat and Mass Transfer 42, no. 20 (1999): 3757-3770.

19. Syuhada, A., M. Hirota, H. Fujita, S. Araki, M. Yanagida, and T. Tanaka. "Heat (mass) transfer in serpentine flow passage with rectangular crosssection." Energy conversion and management 42, no. 15-17 (2001): 1867-1885.

20. Hirota, Masafumi, Hideomi Fujita, Hiroshi Nakayama, and Ahmad Syuhada. "Heat(mass) transfer characteristics in serpentine flow passages with a sharp turn." Nagoya University, School of Engineering, Memoirs 52, no. 1 (2000): 1-52.
21. Rosario, Ariane. "Calculating the Solar Energy of a Flat Plate Collector." Undergraduate Journal of Mathematical Modeling: One+ Two 6, no. 1 (2014): 1.

22. Chabane, Foued, Noureddine Moummi, and Said Benramache. "Experimental study of heat transfer and thermal performance with longitudinal fins of solar air heater." Journal of advanced research 5, no. 2 (2014): 183-192.

23. Mozumder, Atish, Anjani K. Singh, and Pragati Sharma. "Study of cylindrical honeycomb solar collector." Journal of Solar Energy 2014 (2014).

24. [24] Mohammad karim, Ahmadreza, Alibakhsh Kasaeian, and Abdolrazagh Kaabinejadian. "Performance investigation of solar evacuated tube collector using TRNSYS in Tehran." International Journal of Renewable Energy Research (IJRER)4, no. 2 (2014): 497-503.

25. Mishra, Dilip. "Experimental Analysis of Thermal Performance of Evacuated U-Tube Solar Collector." Advance Physics Letters 2, no. 3 (2015).

26. Ihaddadene, Nabila, Razika Ihaddadene, and Abdelwahaab Betka. "Experimental investigation of Using a Novel insulation Material on the Functioning of a Solar Thermal Collector." Journal of Solar Energy Engineering 140, no. 6 (2018): 061001 